\title{
Research on the Presence Greyic Phaeozems in Romania
}

\author{
Anca-Luiza Stănilă (Corresponding author) \\ Department research in soil science, agrochemical and environmental protection \\ Laboratory of soil sciences and sustainable development \\ National Research Institute for Soil Science \\ Agrochemistry and Environment Protection - ICPA \\ 61 Mărăşti Blvd, District 1, 011464, Bucharest, Romania \\ E-mail: luizastanila2011@yahoo.com
}

\begin{abstract}
Cătălin Cristian Simota
Department research in soil science, agrochemical and environmental protection

National Research Institute for Soil Science,

Agrochemistry and Environment Protection - ICPA, Bucharest
\end{abstract}

\author{
Mihail Dumitru \\ Department for physical and chemical analysis \\ National Research Institute for Soil Science, \\ Agrochemistry and Environment Protection - ICPA, Bucharest
}

Received: August 22, 2017 Accepted: September 5, 2017 Published: September 12, 2017 doi:10.5296/jas.v5i3.11837 URL: https://doi.org/10.5296/jas.v5i3.11837 


\section{Macrothink}

\section{Abstract}

Areas under greyic phaeozems of Romania corresponding geographical areas as compared lithostratigraphic are made of clay and marly clay with frequent intercalations of sands and sandstones in a thick package, belonging Sarmatian, respectively, Volhinian and Basarabian, which directly influences the characteristics of the parent material of the soil.

In this way, due to differences in altitude, these soils were formed and evolved deposits vary in granulometric composition, it is represented by loess, loess-like deposit, loam and loess, marly clay.

Thus, we believe that the presence greyic phaeozems of our country in eastern, the genesis and evolution of the important role they have parental materials rich in fine sand fraction $(31-41 \%)$.

Specific these soils is the formation of humic acids and precipitate in place, under the influence of calcium ions, contributing to the development and the individualization of the horizon Am.

Fulvic acids from the breakdown of litter cvercinee does not precipitate in the upper horizon, but migrate to the base, they favoring the migration is known as the iron and aluminum hydroxides and enriching the waste in the lower part of the quartz diagnostic horizon for greyic phaeozems, and a clay horizon B argic migrated upper horizon.

Keywords: pedogenesis, classification, greyic phaeozem, morphological characteristics, physical, hydro and chemical properties

\section{Introduction}

Presence greiyc phaeozems in our country was mentioned for the first time Protopopescu Pache (1907) in northern plain terminal piedmont of Olt and Arges, as the Enculescu (1908) in northwestern Moldova.

Much later (Cernescu and Bucur,1948) separated Plateau Râmnic "podzolic chernozem" stage development as extremely possessing certain common features with the albic luvosol but as shown has proved to be a greyic phaeozem forest.

In 1955, Florea a brief mention of "Soils of Romania" and introduces for the first time on the map greiyc phaeozems country in association with brown soils. The author, however, points out that they occupy narrow strips crossing between forest steppe and forest zone in the East under the influence of continental climate.

An zone of the ground itself was separated from practical field work undertaken to complete the preparation of the material for "Geographical Monograph" of 1958.

Based on soil surveys and field observations, Florea et al. (1963) back with a series of data on greyic phaeozems in Romania.

On taxonomic designation over time there have been some changes, but essential. 


\section{Al Macrothink}

Journal of Agricultural Studies

ISSN 2166-0379

2017, Vol. 5, No. 3

Thus, soil map at 1:1.000.000 (1964), greiyc phaeozems are listed as "grey sylvestre soil", and Chiriţă et al. $(1966,1967)$ introduced the term "grey forest argillic soil".

The "Romanian System of Soil Classification" (1978) were identified by the word synthetic "grey forest soil" class cernisols subtypes typical, cambic, pseudorendzinic, gleyic, stagnic.

Romanian System of Soil Taxonomy (SRTS, 2003, 2012) "grey forest soil" are listed at soil subtypes within phaeozems as the greyic phaeozems.

Greyic phaeozems defined as mollic soils characterized by a horizon Am dark, chroma $\leq 2$ the wet material, the horizon Ame, enriched residual silica, the powdered faces structural aggregates and B argic horizon, having at least in the upper and chroma values $<3.5$ in the wet material, at least on the faces of the structural elements.

\section{Materials and Methods}

The field studies consisted of mapping and spatial reambulating the studied area on maps at 1:10.000 and 1:25.000 scale, with collection of numerous soil and groundwater samples, with observations on relief, micro-relief, parent material, etc.

The basic research and mapping unit of the areas with greyic phaeozems was the soil profile, thus allowing the study of morphological characteristics of the soils. As a result, soils were classified based on intrinsic properties, namely the soil profile, taking into account diagnostic horizons and characteristics.

Soil profiles were located on the ground so that to form a network of studied points. The method of parallel routes, located almost at equal distances has been used, to cover more or less uniformly the whole working area.

The morphological description of soil profiles was done according to the Romanian System of Soil Taxonomy (SRTS, 2003, 2012), ICPA, Bucharest.

In order to establish the soils diagnosis, their morphological features have been taken into account, namely the thickness of morphological horizons, color, texture, structure, composition, adhesion, etc. Soil samples were taken from genetic horizons both in modified and unchanged settings.

In modified settings, soil samples of $20 \mathrm{~cm}$ thickness were taken in bags, for the chemical characterization to be carried. In natural (unchanged) settings, soil samples were taken using a metal cylinder of known volume $\left(200 \mathrm{~cm}^{3}\right)$, to characterize the physical and hydro-physical features, as well as the momentary soil moisture.

\section{The analytical methods used for determination of physical, hydro-physical and chemical:}

\section{Particle size analysis (granulometry):}

- pipette method for fractions $<0.002 \mathrm{~mm}$, including;

- wet sieving method for fractions from 0.002 to $0.2 \mathrm{~mm}$ and dried sieving method for fractions $>0.2 \mathrm{~mm}$ 


\section{I Macrothink}

Journal of Agricultural Studies

ISSN 2166-0379

2017, Vol. 5, No. 3

For the the textural classes and subclasses, we used the Romanian system, according to the Methodology developed for soil studies, ICPA, 1987.

Bulk density (DA) method: metal cylinder of known volume $\left(200 \mathrm{~cm}^{3}\right)$ for the momentary soil moisture.

Total porosity $(\boldsymbol{P T})$ : by computing $\mathrm{PT}=(1-\mathrm{DA} / \mathrm{D}) * 100$

The coefficient hygroscopicity $(\boldsymbol{C H})$ : drying at $105{ }^{0} \mathrm{C}$ of a sample of soil moistened in advance in equilibrium with an atmosphere saturated with water vapor (in the presence of a solution of $\left.\mathrm{H}_{2} \mathrm{SO}_{4}-10 \%\right)$ - \% by weight (\% g/g).

Withering coefficient (CO): by calculation, by multiplication with 1.5 coefficient hygroscopicity, determined by the method of modified Mitscherlich - $\%$ by weight $(\% \mathrm{~g} / \mathrm{g})$.

$\mathrm{CO}(\%)=0,05+0,35 \mathrm{~A}$, where:

$\mathrm{A}=$ clay content $<0,002 \mathrm{~mm}$

Total water capacity $(\boldsymbol{C T})$ : by calculation from the formula CT= PT/DA, \% by weight.

Useful water capacity $(\boldsymbol{C U})$ by calculation:

$\mathrm{CU}=\mathrm{CC}-\mathrm{CO}, \%$ by weight.

Field capacity $(\boldsymbol{C C})$. This can be determined by the direct method using the platform or the estimated indirect way. On indirect way are several possibilities:

- based on texture and bulk density;

- on the basis of equivalent moisture and bulk density;

- on the basis of the suction curve (measured on samples with the alignment unchanged).

Water permeability $(\boldsymbol{K})$ is determined by several methods, one of which, in the laboratory on samples with unchanged alignment, taken in the metal cylinder, the method I.C.P.A.

Organic matter (humus) determined by volumetric method Walkley - Black wet oxidation after the change Gogoaşă (Stoica et al., 1986).

Total Nitrogen (Nt): Kjeldahl method disintegration $\mathrm{H}_{2} \mathrm{SO}_{4}$ at $350{ }^{0} \mathrm{C}$, a catalyst of potassium sulfate and copper sulfate.

Phosphorus accessible (P mobile): method-Riehm-Domingo and dosed with colorimetric molybdenum blue method after Murphy-Riley (reduction with ascorbic acid).

Potassium (K mobile) accessible: after extraction method Egner-Riehm-Domingo and determination by flame photometry.

$\boldsymbol{p H}$ : potenţiometric, determined the combined glass electrode and a calomel, in aqueous suspension the soil/water ratio of $1 / 2,5$.

Sum of bases (SB): extraction using 0.05 n hydrochloric acid (Kappen-Schofield- Chiriţă method).

The base saturation degree (V\%) and total cation exchange capacity (T me/100 g soil), by calculation.

Hydrolytic acidity (Ah me /100 $\mathrm{g}$ soil) was determined by extraction with $1 \mathrm{~N}$ sodium acetate solution buffered to $\mathrm{pH}=8.3$.

Total cation exchange capacity ( $\mathrm{T}$ me/100 $\mathrm{g}$ soil) was determined with the following formula: $\mathrm{T}(\mathrm{me} / 100 \mathrm{~g}$ soil $)=\mathrm{SB}+\mathrm{Ah}$

Interpretation of the results has been submitted in accordance with "Methodology developing soil studies", ICPA Bucharest, 1987, provided for in current legislation on the 


\section{Macrothink}

subject.

Block diagram representing the landscape ahead, constitute a means of rendering landforms. For its construction, using an isometric projection in which the vertical axis is an axonometric $\mathrm{Z}$, and $\mathrm{X}$ and $\mathrm{Y}$ axes form between them an angle of $120^{\circ}$. Making block diagram is obtained based on the interpretation of field and laboratory data.

\section{Results and Discussions}

\subsection{Spreading and Training Conditions}

- Greyic phaeozems in Romania a relatively low spread. They appear on larger areas continuing to argic chernozems wetter areas in Suceava Plateau, Jijia Plain, Central Moldavian Plateau, Northern Dobrogea and Moldavia Subcarpathians.

- Greyic phaeozems were formed under a plain relief, plateau, glacis, low hills and terraces.

- Parental material is represented by loess-like deposit, loams and loess, argillaceous marl, etc. (Figure 1).

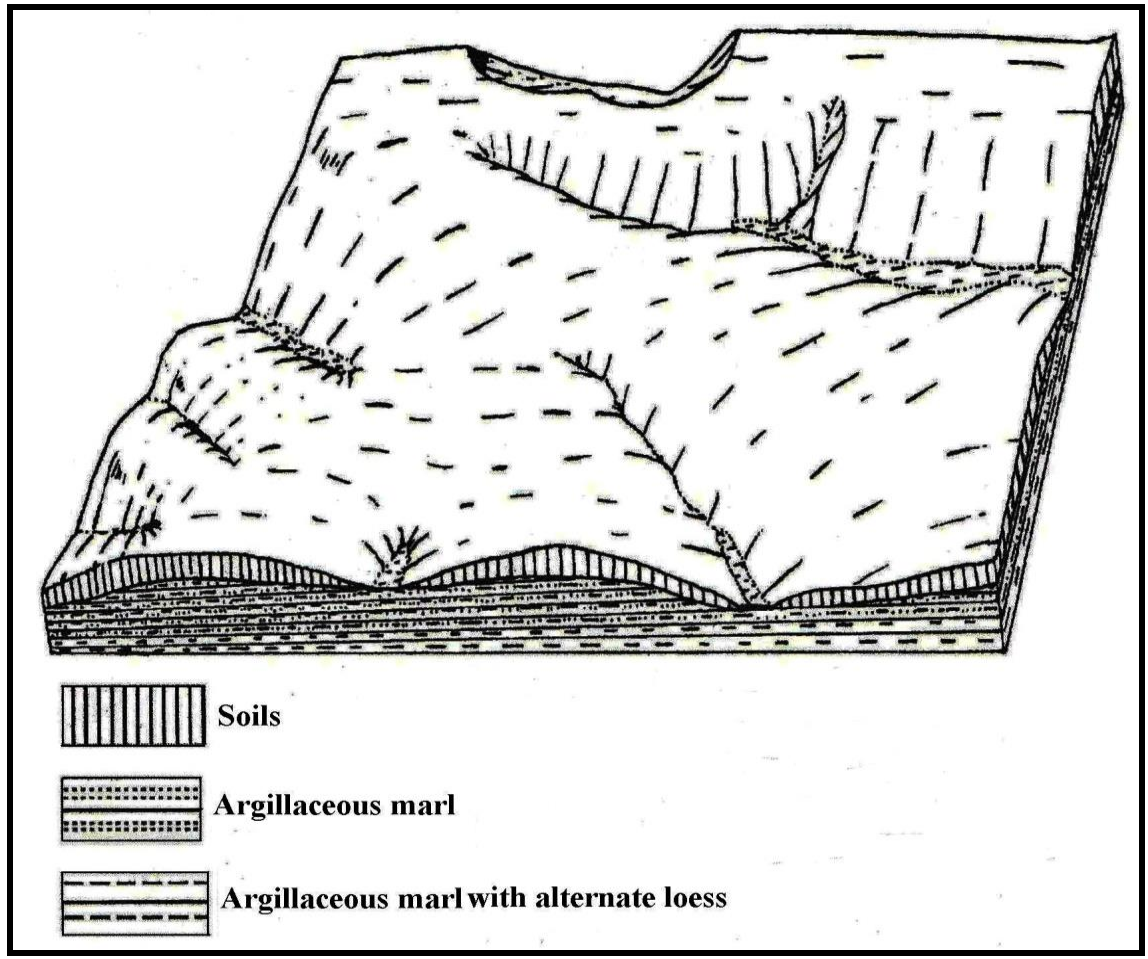

Figure1. Block diagram in Suceava Plateau (Darabani spur hilly)

The climate is relatively wet and cool, characterized by the annual average temperature of $7-9{ }^{0} \mathrm{C}, 550-640 \mathrm{~mm}$ annual rainfall and potential evapotranspiration is almost equal to precipitation.

Natural vegetation areas with greyic phaeozems feature is specific forest steppe and not the forest, as advocated in some publications. 


\section{Macrothink}

Journal of Agricultural Studies

ISSN 2166-0379

2017, Vol. 5, No. 3

Forest clumps occurring consist of Quercus pedunculiflora, Tilia tomentosa, Q.pubescens and mixed with T.cordata, Carpinus betulus, Fraxinus excelsior and Acer campestre.

Grass vegetation in forest represented by a specific mull flora which is missing Brachypodium silvaticum, Viola silvestris, Carex pilosa, Asarum europaeum, Poa nemoralis, Potentilla argentea, Dactylis glomerata, etc.

Carefully examined greyic phaeozems formed under these conditions has a series of morphological, some of which are determined by the grassy other forest vegetation.

Thus, they contain a significant amount of dark humus eluvial horizon and as mirrors of humus in the upper horizon B, which they cambic chernozems.

With all this accumulation of humus, they show more obvious in the second half of the upper horizon and a dusting with quartz that prints a tint gray character received would appear as a result of the process of podzolization under the influence of vegetation forest, but can just as well be due to intake wind of quartz sand deposits currently Volhiniene.

\subsection{The Morphological Characteristics}

Greyic phaeozems presents a profile of type Am-Ame-Bt-C or Cca developed (Figure 2).

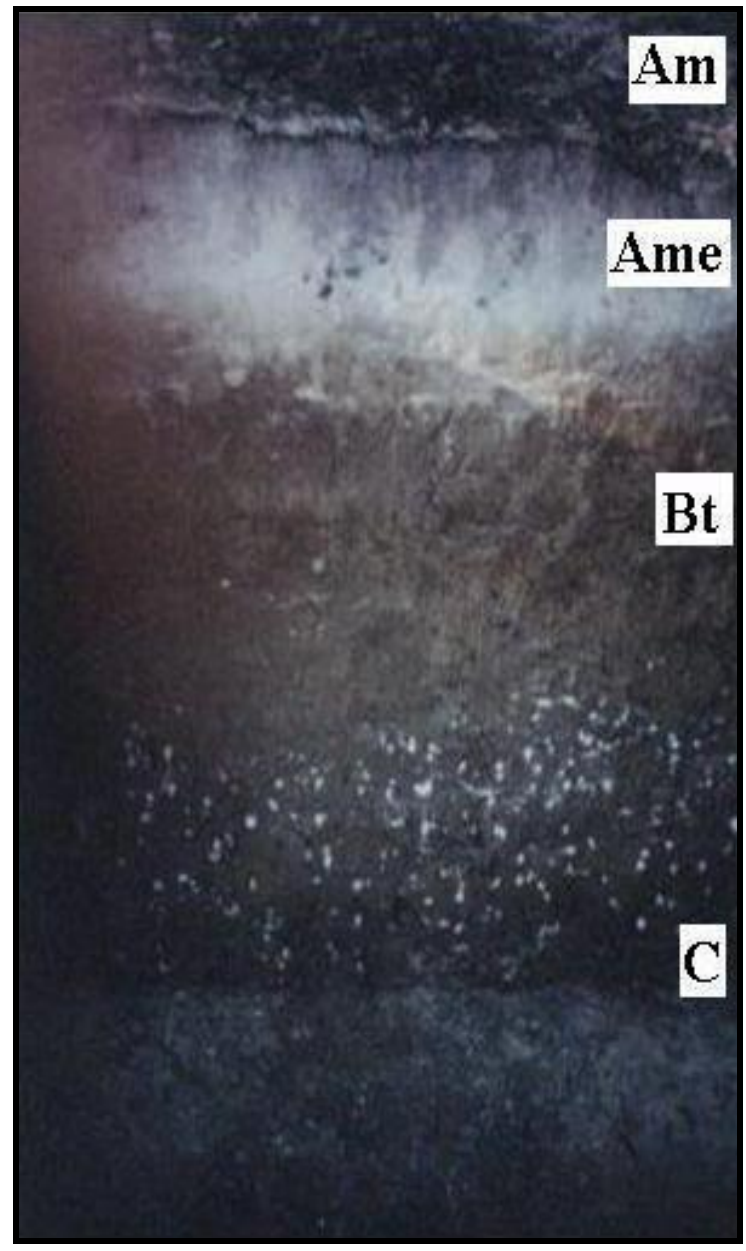

Figure 2. Greyic phaeozem in the Jijia Plain. 
$A m$ horizon, with a 30-40 cm thickness, is very dark brown (10YR 2/2) when humid, very dark gray, dark gray (10YR 3.5/1) when dry, grained structure, it has poor plastic, thin adhesive, loose, porous and thin grass roots or root contains wood, gradually-clear passage;

Ame horizon, 12-14 cm thick, is characterized by the same color as the horizon Am when humid, but lighter than dry (10YR 4/1), large grained structure, light plastic, thin adhesive, dusting with grains sand and dust, small and medium pore frequent and herbaceous or woody roots contain common gradual transition;

$A B$ horizon, $15-20 \mathrm{~cm}$ thick, the color becomes easy opening very dark gray brown (10YR 3/2) when humid, gray dark gray-brown (10YR 4/4.5) when dry, have the structure small sub-angular polyhedral-average strong silica dusting the root directory and small and medium pores, clear passage;

$B t$ horizon, is divided mainly by color, texture and structure as follows:

$B t_{1}$ subhorizon developed in the $45-50 \mathrm{~cm}$, has a textured silty clay loam- clay medium, dark brown (10YR 3/3) to grayish brown discoloration and very dark brown (10YR 3/2-4/3) in the when humid to gray-brown (10YR 4.5/2) in when dry, columnoid-prismatic structure, dusting with silica originating from the upper horizon, clay films on the faces of the structural elements, frequent small pores and moderate adhesive and the plastic is present, the gradual passage;

$B t_{2}$ subhorizon, 55-60 cm thick, has a clayey-loamy texture, dark yellowish brown (10YR 4/4) when humid and brown (10YR 5/3) with yellowish brown spots (10YR 5/4) in when dry, columnoid-prismatic structure film clay faces structural agregates, small pores very frequent and show brittle, firm wet, rough dry, moderately plastic and adhesive iron-manganese concretion and leakage of humus on the old roots, crotovina, route gradually;

$\mathrm{Bt}_{3}$ subhorizon, 25-30 $\mathrm{cm}$ thick, presents clayey-loamy texture, yellowish brown (10YR 5/4) in when humid, columnoid-prismatic structure, small and medium-sized pores, clay films on the faces of the structural elements, iron-manganese concretion, crotovina rare, crossing net;

$C$ horizon often lies in the $180-190 \mathrm{~cm}$, it has a dark yellowish brown (10YR 4/4) when humid and light yellowish brown (10YR 5/6) when dry, without structure, friable wet, loose makes effervescence mass and containing $\mathrm{CaCO}_{3}$ in the form of concrete and small veins.

\subsection{Physical and Hydro-Physical Characteristics}

Greyic phaeozems have a clayey-loamy texture. Clay content is $32-33 \%$ in horizon Am and $34-35 \%$ in Ame, then slightly increase the profile without exceeding 43\% (Table 1), index of texture differentiation hovering around 1.2-1.3. There are loose in the upper horizon (-2.9 to $18.3 \%)$, moderately compacted in Bt (14-15\%). Very low bulk density Am $\left(1.08\right.$ to $\left.1.28 \mathrm{~g} / \mathrm{cm}^{3}\right)$ becomes higher in $\mathrm{Bt}(1.50$ to $1.51 \mathrm{~g} / \mathrm{cm} 3)$, and the porosity of soil has high and very high values on the surface $(52-60 \%)$. 
Table 1. Physical and hydro-physical data on greyic phaeozems

\begin{tabular}{ccccccccccccc}
\hline Horizon & $\begin{array}{c}\text { Depth } \\
\text { (cm) }\end{array}$ & \multicolumn{4}{c}{ Granulometric composition } & \multicolumn{4}{c}{ Physical and hydro-physical properties } \\
& & $\mathbf{m m}$ & $\mathbf{0 , 0 0 2 - 0 , 0 2}$ & $\mathbf{0 , 0 2 - 0 , 2}$ & $\mathbf{0 , 2 - 2}$ & $\mathbf{D A}$ & $\mathbf{P T}$ & $\mathbf{C O}$ & $\mathbf{C C}$ & $\mathbf{C U}$ & $\mathbf{C T}$ & $\mathbf{K}$ \\
& & $\mathbf{m m}$ & $\mathbf{m m}$ & $\mathbf{m m}$ & $\mathbf{g} / \mathbf{c m}^{\mathbf{3}}$ & $\mathbf{\%}$ & $\mathbf{\%}$ & $\mathbf{\%}$ & $\mathbf{\%}$ & $\mathbf{\%}$ & $\mathbf{m m} / \mathbf{h}$ \\
\hline $\mathrm{Am}$ & $0-20$ & 32,8 & 33,0 & 34,2 & 0,0 & 1,08 & 59,6 & 10,8 & 26 & 15,2 & 55,1 & 20,6 \\
$\mathrm{Ame}$ & $22-34$ & 34,5 & 29,8 & 35,7 & 0,0 & 1,28 & 52,1 & 8,7 & 25 & 16,3 & 40,7 & 11,5 \\
$\mathrm{AB}$ & $34-53$ & 39,6 & 27,5 & 32,9 & 0,0 & 1,39 & 48,0 & 9,6 & 25 & 15,4 & 34,5 & 12,3 \\
$\mathrm{Bt}_{1}$ & $53-100$ & 42,5 & 27,7 & 29,8 & 0,0 & 1,41 & 47,5 & 10,5 & 25 & 14,5 & 33,6 & 17,9 \\
$\mathrm{Bt}_{2}$ & $100-160$ & 41,3 & 30,1 & 32,8 & 0,0 & 1,50 & 44,1 & 11,5 & 24 & 12,5 & 29,4 & 20,7 \\
$\mathrm{Bt}_{3}$ & $160-191$ & 37,1 & 30,8 & 32,1 & 0,0 & 1,51 & 43,6 & 12,1 & 24 & 11,9 & 28,8 & 0,3 \\
$\mathrm{Ck}$ & $195-285$ & 35,5 & 25,1 & 39,4 & 0,0 & 1,45 & 45,7 & 10,5 & 23 & 12,5 & 31,5 & 6,9 \\
\hline
\end{tabular}

Field capacity is large-sized in all cases (25-26\%), medium withering coefficient (from 8.7 to $11.5 \%$ ), water and the available moisture holding capacity is very high (15.2 to 16.3$)$.

The permeability is high (11.5 to $20.7 \mathrm{~mm} / \mathrm{h}$ ), except for subhorizon $\mathrm{Bt}_{3}$ and $\mathrm{C}$ the values are small-sized $(0.3$ to $6.4 \mathrm{~mm} / \mathrm{h})$.

\subsection{Chemical Characteristics}

Greyic phaeozems generally contain 5-12\% humus in the upper horizon, when the wood is below $3.5 \%$ in the culture. It has a moderate acidic reaction (5.20 to 5.80) (Table 2).

Table 2. Chemical data on greyic phaeozems

\begin{tabular}{cccccccccc}
\hline Horizon & $\begin{array}{c}\text { Depth } \\
(\mathbf{c m})\end{array}$ & $\begin{array}{c}\mathbf{p H} \\
\left(\mathbf{H}_{\mathbf{2}} \mathbf{O}\right)\end{array}$ & $\begin{array}{c}\text { Humus } \\
\mathbf{\%}\end{array}$ & $\mathbf{C} / \mathbf{N}$ & $\begin{array}{c}\mathbf{T} \mathbf{m e} / \mathbf{1 0 0} \mathbf{g} \\
\mathbf{s o l}\end{array}$ & $\begin{array}{c}\mathbf{V} \\
\mathbf{\%}\end{array}$ & $\begin{array}{c}\mathbf{N t} \\
\mathbf{\%}\end{array}$ & $\begin{array}{c}\mathbf{P} \\
\mathbf{p p m}\end{array}$ & $\begin{array}{c}\mathbf{K} \\
\mathbf{p p m}\end{array}$ \\
\hline $\mathrm{Am}$ & $0-20$ & 5,80 & 6,12 & 15,7 & 19,82 & 67,8 & 0,264 & 12 & 130 \\
$\mathrm{Ame}$ & $22-34$ & 5,52 & 2,34 & 15,5 & 14,55 & 42,1 & 0,102 & 10 & 111 \\
$\mathrm{AB}$ & $34-53$ & 5,44 & 1,86 & 12,6 & 16,68 & 56,3 & 0,100 & 4 & 123 \\
$\mathrm{Bt}_{1}$ & $53-100$ & 5,30 & 1,32 & 11,5 & 15,40 & 64,6 & 0,078 & - & - \\
$\mathrm{Bt}_{2}$ & $100-160$ & 5,20 & - & - & 14,57 & 79,4 & - & - & - \\
$\mathrm{Bt}_{3}$ & $160-191$ & 5,66 & - & - & 14,62 & 88,6 & - & - & - \\
$\mathrm{Ck}$ & $195-285$ & 7,42 & - & - & - & 100,0 & - & - & - \\
\hline
\end{tabular}

$\mathrm{C}: \mathrm{N}$ ratio is slightly higher than the cambic chernozems (15.5).

Effective cation-exchange capacity is characterized by low values (from 14.57 to $19.82 \mathrm{me} / 100 \mathrm{~g}$ soil), and the degree of saturation mesobasic horizon Am (67.8\%), decreases abruptly in Ame $(42,1 \%)$, and reach the base to fully saturated horizontally C.

For the supply of nutrients, it is in the middle of the upper horizon nitrogen (0.07 to $0.25 \%)$ if the soil is cultivated and low profile with respect to phosphorus (10-12 ppm) and potassium (111-130 ppm). 


\section{Macrothink}

\section{Conclusions}

We believe that the formation of the soils had an important role in the parent material rich in fine sand fraction (31-62\%) and to a lesser extent climate and vegetation.

If we take into consideration the fact that in the area of greyic phaeozems or near appear to date rocks (sandstones, sands) generating grains of quartz, it is possible that these soils to present duty, first, the intake wind of coarse material and secondly, pedogenetic processes specific.

Fertility greyic phaeozems is good to very good due to both physical and chemical characteristics (texture, structure, reaction moderately weak acid) and the corresponding supply humus, nitrogen and phosphorus.

They have a predominantly agricultural use, is used for field crops (cereals, industrial plants) (Figure 3, 4, 5, 6), but are used in viticulture. The most famous vineyards in our country, such as those from Pietroasele-Buzău, Odobeşti, Panciu, Nicoreşti, Cotnari are located on these soils.

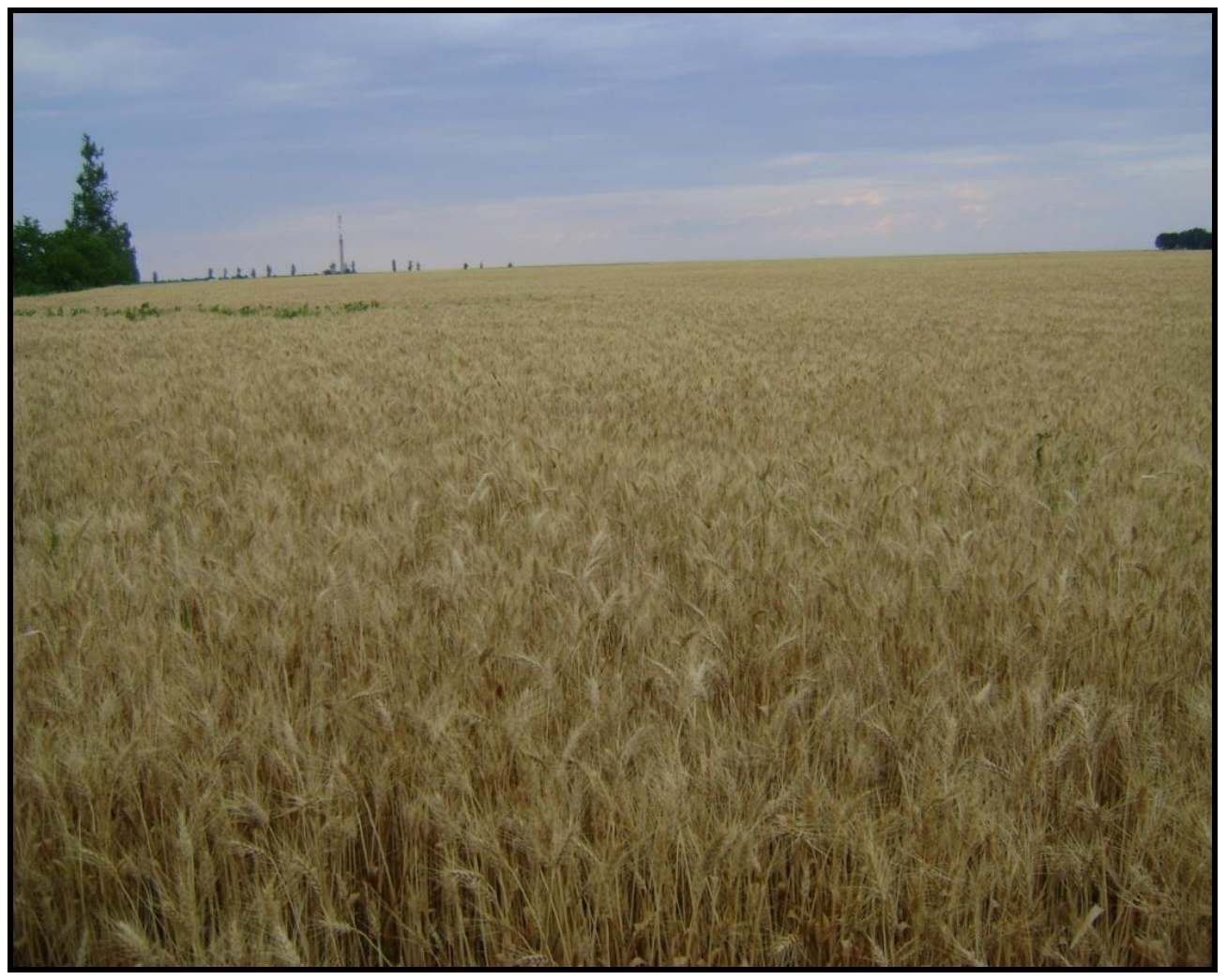

Figure 3. Culture of wheat in the Jijia Plain. 


\section{Macrothink}

Journal of Agricultural Studies

ISSN 2166-0379

2017, Vol. 5, No. 3

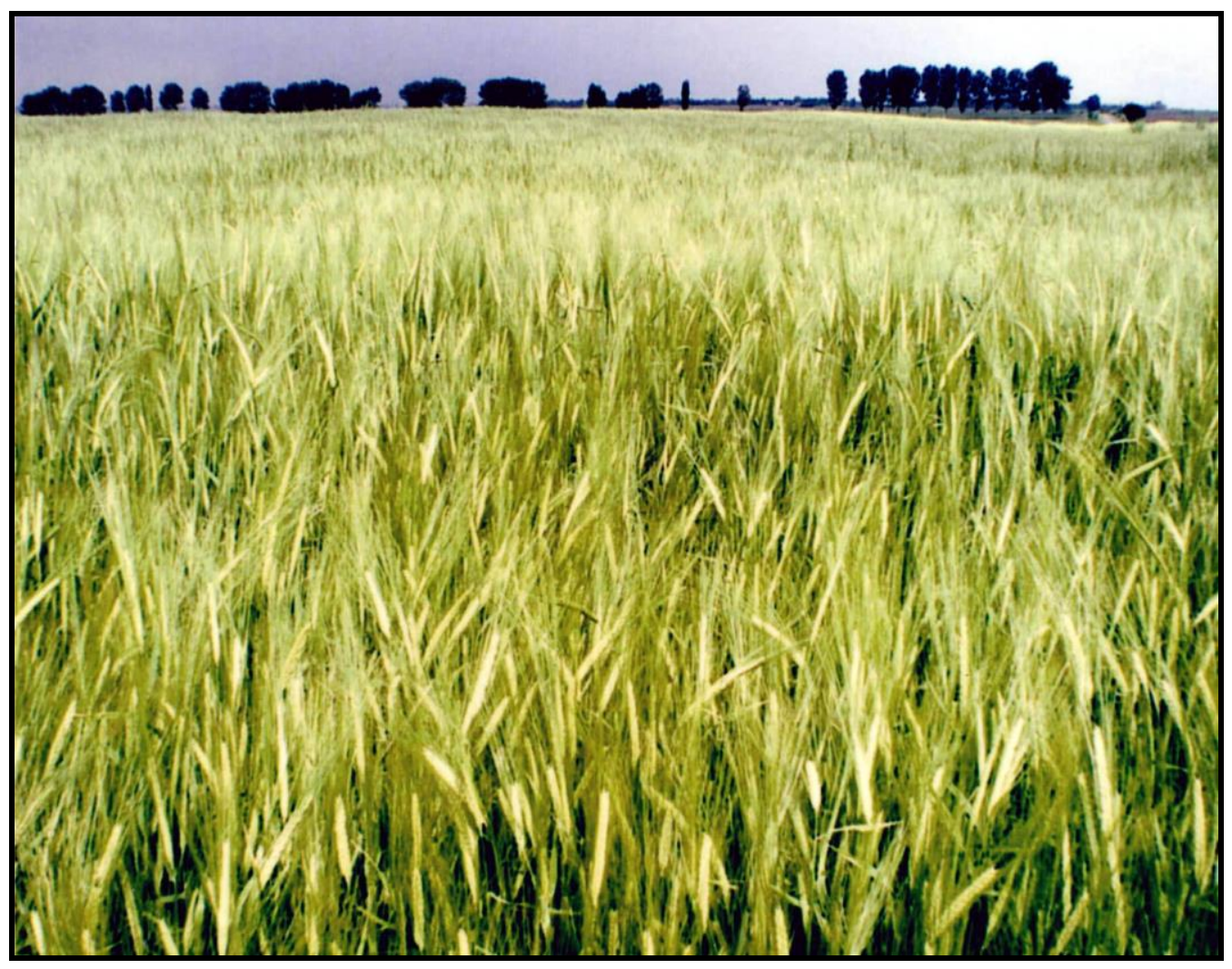

Figure 4. Culture of barley in the Jijia Plain.

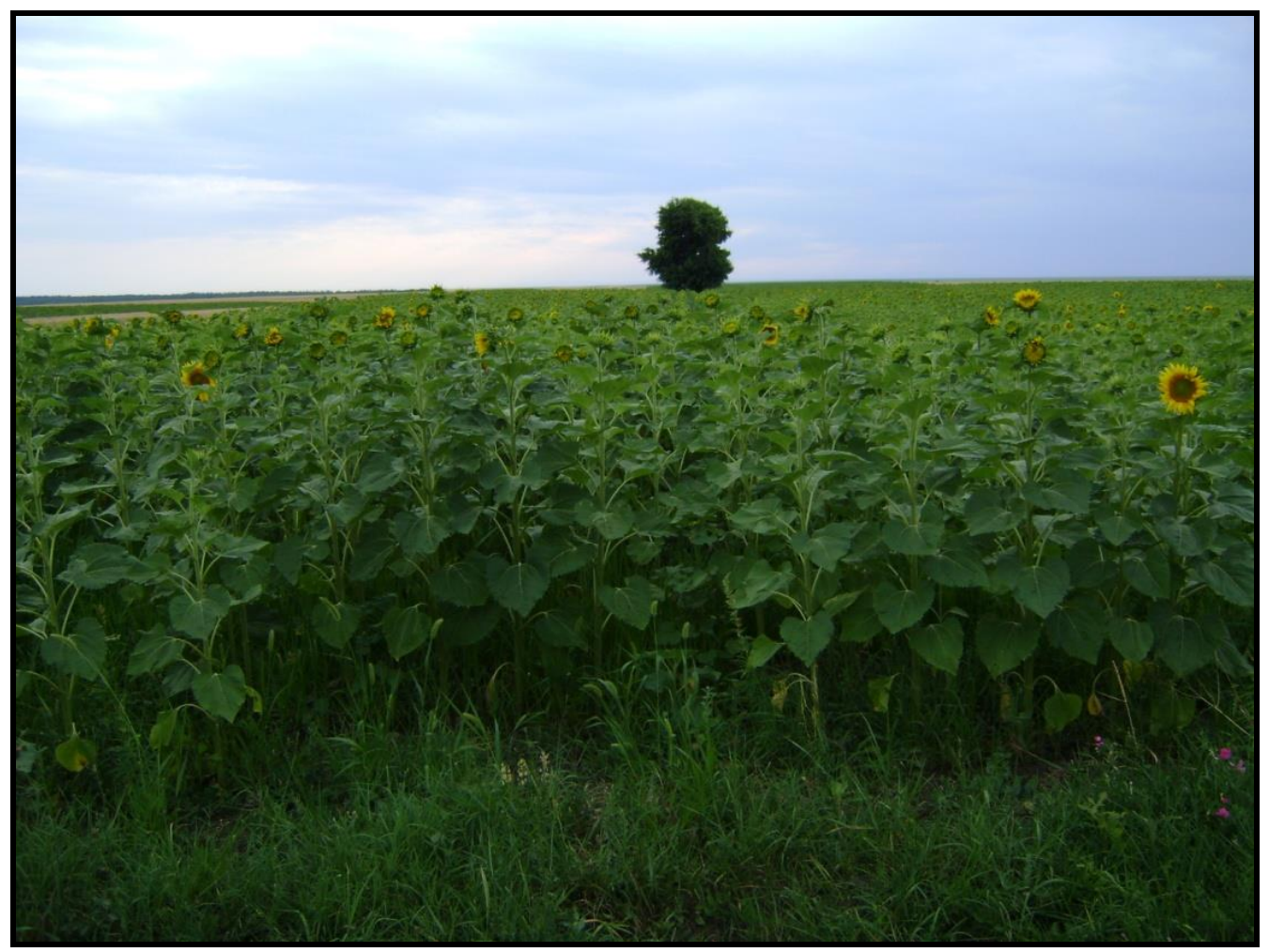

Figure 5. Culture of sunflower in the Jijia Plain. 


\section{MInstitute ${ }^{\text {Mech }}$}

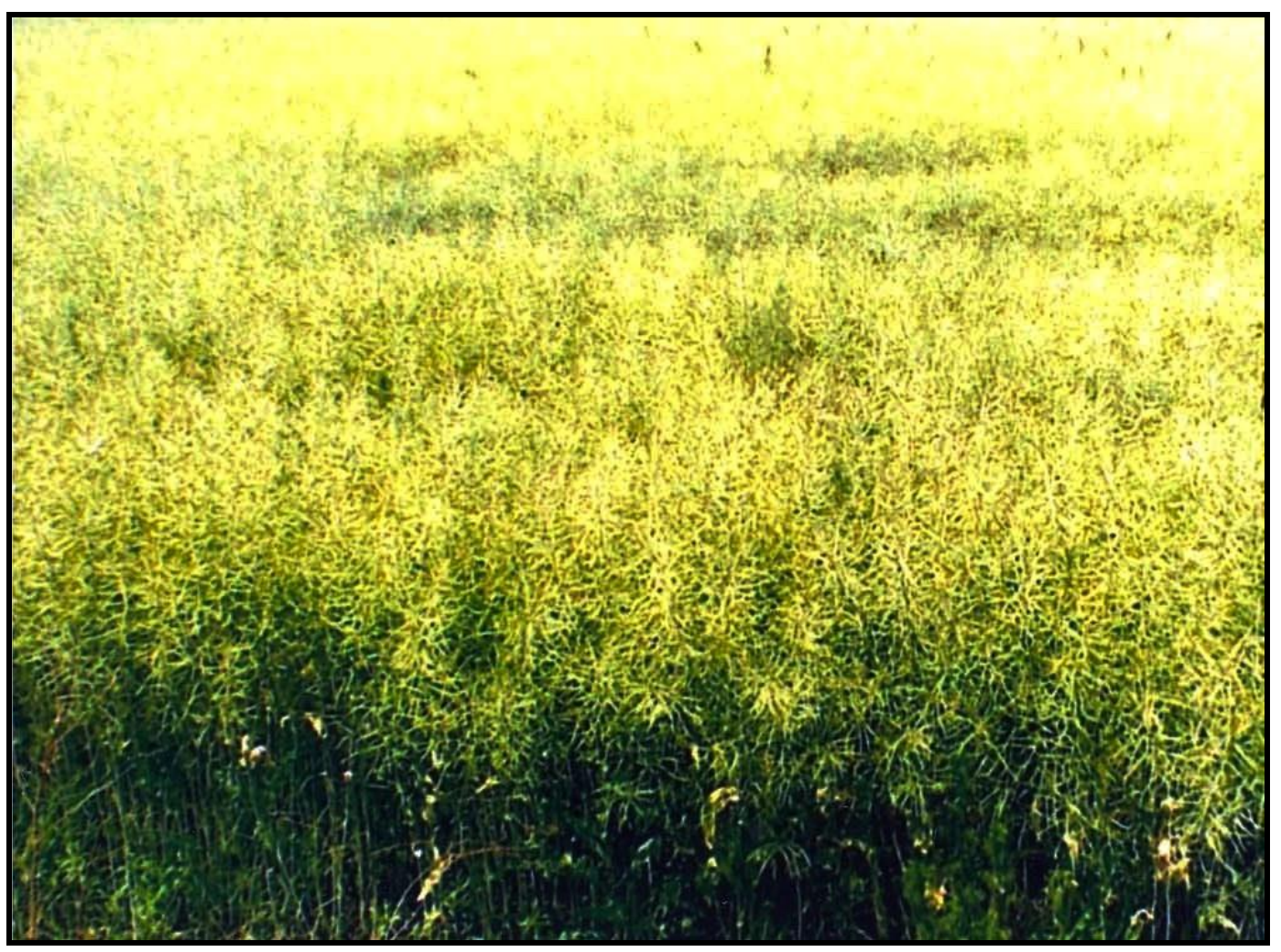

Figure 6. Culture of rape in the Jijia Plain.

Greyic phaeozems improve their productive qualities has been grown. However, the need for fertilizers is higher than cambic and argic.

Typically, well-recovered mineral nitrogen fertilizers and manure. In addition, we recommend the correct application of agricultural technique, sufficient to ensure normal development of crops in this group of soils.

\section{Acknowledgements}

We are very thankful to Department research in soil science, agrochemical and environmental protection, Laboratory of soil sciences and sustainable development for providing the necessary facilities to carry out this work.

\section{Conflict of interest}

We declare that we have no conflict of interest.

\section{References}

Băcăuanu, V., Barbu, N., Pantazică, Maria, Ungureanu, Al., \& Chiriac, D. (1980). Moldavian Plateau. Scientific and Encyclopedic Publishing, Bucharest.

Borlan, Z., \& Răuţă, C. (1981). Agrochemical soil analysis methodology in order to establish the necessary amendments and fertilizers. ICPA, Bucharest.

Bucur, N. (1953). Elemental characterization of pedologic complex Jijia-Bahlui Depression. Studies and Scientific Research. Academy R.P.R. Iaşi Branch, No. 1-4 Year IV /1953. 
Bucur, N. (1954). Series soil of Ozana-Topolniţa Depression. Studies and Scientific Research, Academy R.P.R., Iasi Branch, No.3-4 Year 4 V/1954.

Canarache, A. (1990). Soil physics. Ceres Publishing House, Bucharest, 268.

Cernescu, N. (1934). Facteurs de climat et zones de sol en Roumanie. Geological Institute of Romania, Technical and Economic Studies, Series C, No. 2, Bucharest.

Cernescu N., \& Bucur, N. (1952). The results from soil mapping Ramnicu Sarat County. D.S., Geological Institute of Romania, XXXVI (1948-1949), Bucharest.

Cernescu, N., \& Florea, N. (1958). Zoning pedogeographic R.P.R. Geographical achievements R.P.R., during 1947-1957, Bucharest.

Conea, Ana, Vintilă, Irina, \& Canarache, A. (1977). Dictionary of soil science. Scientific and Encyclopedic Publishing, Bucharest, 671.

Enculescu, P. (1913). Research general agrogeology in NV Moldova. Report on the work of courts. Geological Institute of Romania, Bucharest.

Florea, N., \& Parichi, M. (1967). Contribution to knowledge soils in the upper basin of Sitna. D.S., Vol. LIII / 2 (1965-1966), Bucharest.

Florea, N., Munteanu, I., Rusu, C., Dumitru, M., Ianoş, Gh., Răducu, Daniela, Rogobete, Gh., \& Ţărău, D. (2012). Romanian System of Soil Taxonomy. Sitech Publishing House, Bucharest, 206.

Ispas, Şt., \& Stănilă, Anca-Luiza (2015). Romanian soils. Publisher Valahia University Press, Târgovişte, 246.

Lupaşcu, Gh., Parichi, M., Stănilă, Anca-Luiza, \& Florea, N. (2003). References pedological Romania. Terra Nostra Publishing House, Iaşi, 637.

Obrejeanu, Gr., \& colab. (1958). Agropedologic study of the experimental stations of I.C.A.R., Bucharest. Romanian Academy Publishing House, Bucharest, 152.

Parichi, M., Stănilă, Anca-Luiza, Staicu, Filuţa, \& Moise, Irina (1998). Contributions to the knowledge of soils of low Hills Tutovei. Annals of Spiru Haret University, Geography Series, No. 1. Romania for Tomorrow Publishing House, Bucharest, 33-38.

Parichi, M., Stănilă, Anca-Luiza, \& Cruceru, N. (2006). Soils main relief units in Romania. Romania for Tomorrow Publishing House, Bucharest, 179.

Posea, Gr., \& Cruceru, N. (2005). Geomorphology Romania. Romania for Tomorrow Publishing House, Bucharest, 364.

Stănilă, Anca-Luiza, \& Parichi, M. (2001). Soils mapping. Romania for Tomorrow Publishing House, Bucharest, 160.

Stănilă, Anca-Luiza, \& Parichi, M. (2003). Soils of Romania. Romania for Tomorrow Publishing House, Bucharest, 191. 


\section{Macrothink}

Journal of Agricultural Studies

ISSN 2166-0379

2017, Vol. 5, No. 3

Stănilă, Anca-Luiza, \& Parichi, M. (2005). Glossary of soil science. Romania for Tomorrow Publishing House, Bucharest, 108.

Stănilă, Anca-Luiza (2006). Biogeography. Romania for Tomorrow Publishing House, Bucharest, 254.

Stănilă, Anca-Luiza, \& Parichi, M. (2012). What you need to know about the soil they work. Romania for Tomorrow Publishing House, Bucharest, 72.

Stănilă, Anca-Luiza, Dumitru, M., \& Simota, C. (2017). Contributions to the knowledge of soil resources of Cuca Plain. Journal of Agricultural Studies, Vol. 5, No.2, https://doi.org/10.5296/jas.v5i2.11208, 13-31.

Stoica, Elena, Răuţă, C. \& Florea, N. (1986). Methods for chemical analysis of soil. ICPA, Bucharest, 487.

(1980). Romanian system of soil classification. ICPA, Bucharest.

(1987). Development methodology soil studies (3 Volume). ICPA, Bucharest, 726.

(2008). The climate of Romania. National Meteorological Administration. Romanian Academy Publishing House, Bucharest, 365.

\section{Copyright Disclaimer}

Copyright for this article is retained by the author(s), with first publication rights granted to the journal.

This is an open-access article distributed under the terms and conditions of the Creative Commons Attribution license (http://creativecommons.org/licenses/by/4.0/). 